\title{
Numerical parametric study of a cooling system for an LNG storage tank
}

Mohamed Haddar*, Moez Hammami, and Mounir Baccar

CFDTP, National School of Engineers of Sfax (ENIS), 3038, Tunisia

Received: 31 July 2018 / Accepted: 10 December 2018

\begin{abstract}
The study of the cooling system of a Liquefied Natural Gas (LNG) storage tank is vital for the safety of the installation. The objective of this paper is to develop cooling baffles capable of reducing the heat gain from the environment leading to a loss of LNG quantity, keeping the Boil-Off Gas (BOG) under control. For this purpose, a specific code based on the finite volume method was developed to improve our knowledge of the hydrodynamic and thermal behaviors of LNG in the cylindrical tank. In addition, the effect of the number, position and dimension of the baffles on the flow structure of LNG were determined. The obtained results indicated that the location of the baffles at the top of the tank nearby the vicinity of the wall would yield a better cooling of the LNG. Moreover, we emphasized that a number of six baffles would give rise to a better heat transfer. For a design purpose, the Nusselt numbers on the lateral surface and on the baffles have been correlated as functions of Rayleigh and baffle numbers.
\end{abstract}

\section{Nomenclature}

AR Aspect ratio, $H / D$

$\boldsymbol{D}$ Tank diameter $[\mathrm{m}]$

g Gravity $\left[\mathrm{m} \mathrm{s}^{-2}\right]$

$\boldsymbol{H} \quad$ Height of LNG inside the tank $[\mathrm{m}]$

$\bar{h} \quad$ Average heat transfer coefficient $\left[\mathrm{W} \mathrm{m}^{-2} \mathrm{~K}^{-1}\right]$

$\boldsymbol{P}$ Pressure $[\mathrm{Pa}]$

$r \quad$ Radial position $[\mathrm{m}]$

$\boldsymbol{T}$ Temperature $\left[{ }^{\circ} \mathrm{C}\right]$

$\boldsymbol{t} \quad$ Time $[\mathrm{s}]$

$\boldsymbol{u}, \boldsymbol{v}, \boldsymbol{w}$ Velocity components $\left[\mathrm{m} \mathrm{s}^{-1}\right]$

$z \quad$ Axial position $[\mathrm{m}]$

\section{Dimensionless variables}

$p \quad$ Dimensionless pressure

$r, \theta, z \quad$ Dimensionless cylindrical coordinates

$T \quad$ Dimensionless temperature

$t \quad$ Dimensionless time

$u, v, w$ Dimensionless velocity components

\section{Dimensionless numbers}

$\mathrm{Nu} \quad$ Nusselt number

$\operatorname{Pr} \quad$ Prandtl number, $v / \alpha$

\footnotetext{
* Corresponding author: haddar.mohamed@gmail.com
}

$R a \quad$ Rayleigh number, $g \beta \Delta T_{0} H^{3} / \alpha v$

\section{Greek symbols}

$\begin{array}{ll}\alpha & \text { Thermal diffusivity }\left[\mathrm{m}^{2} \mathrm{~s}^{-1}\right] \\ \beta & \text { Thermal coefficient of expansion }\left[\mathrm{K}^{-1}\right] \\ \lambda & \text { Thermal conductivity }\left[\mathrm{W} \mathrm{m}^{-1} \mathrm{~K}^{-1}\right] \\ v & \text { Kinematic viscosity }\left[\mathrm{m}^{2} \mathrm{~s}^{-1}\right] \\ \rho & \text { Density }\left[\mathrm{kg} \mathrm{m}^{-3}\right] \\ \varphi_{l} & \text { Lateral heat flux density }\left[\mathrm{W} \mathrm{m} \mathrm{m}^{-2}\right]\end{array}$

\section{Subscripts}

$\begin{array}{ll}a v & \text { Average value } \\ b & \text { Baffle side surface } \\ l & \text { Lateral tank surface } \\ \max & \text { Maximum value } \\ 0 & \text { Reference value }\end{array}$

\section{Introduction}

Natural gas has proven to be a reliable and efficient energy source that burns much cleaner than other fossil fuels. It plays the role of a safe fuel in a small package. It is condensed to a liquid by cooling it to about $-162{ }^{\circ} \mathrm{C}$ at atmospheric pressure, reducing its volume by a factor of 
600 similar [1]. Afterwards, LNG is transported by ship to terminals and then stored in super-insulated tanks. Since the storage tank cannot have a perfect insulation, heat is transferred to LNG due to the large temperature gap between the inside of the tank and the ambient [2]. The heat gains, through the tank walls, cause an increase of the LNG temperature leading to a loss of LNG quantity [3], as Boil-Off Gas (BOG), by a continuous vaporization.

Previous 2D convection studies, in a cylindrical enclosure, looked at the problem from a numerical [4-6], an experimental $[7,8]$ or a combination of experimental, analytical and numerical perspectives [9]. Papanicolaou, and Belessiotis [5], in particular, investigated the behavior of natural convection in a cylindrical enclosure at the boundary between laminar and turbulent flow numerically. Different turbulence models were tested and the two-layer model agreed well with experimental results at a moderated Rayleigh number $\left(R a \leq 10^{5}\right)$. Other researchers [10-13] dealt with three dimensional laminar natural convection problems. More specifically, Schneider and Straub [12] demonstrated by a numerical study and experimentally verified the dependence of the flow field and the heat transfer on the inclination angle of the cylinder.

Concerning the reservoir cooling application, De Césaro Oliveski [14] conducted a two-dimensional work to study the transient cooling process in a vertical cylindrical tank and presented a new correlation for the Nusselt number at high Prandtl number based on aspect ratio, external overall heat transfer coefficient and Grashof number. Moreover, Rodríguez et al. [15] developed a parametric study to understand the unsteady natural convection phenomena inside a vertical storage tank during the cooling process using a non-dimensional method.

Closely related to LNG tank problems, an early study was conducted to investigate the rate of heat gain at steady state in LNG storage tanks by using two mathematical models [16]. It was concluded that the optimal aspect ratio $(\mathrm{H} / \mathrm{R})$ should approximately be the unity for minimal heat gain and, by decreasing the fullness factor (the LNG volume occupied percentage, $\mathrm{Z} / \mathrm{H}$ ), a significant increase of the heat gain rate would occur.

Recently, Khelifi Touhami et al. [17] studied laminar natural convection in a storage tank filled with LNG using a numerical method based on the two-dimensional approach. These researchers aimed to understand the evaporation problem occurring in an LNG tank by conducting a parametric study. Their main finding was that the increase of the Rayleigh number at constant aspect ratio, or the reduction of aspect ratio at a constant Rayleigh, enhanced the heat transfer. In addition, due to this heat gain, it was observed that the evaporative flux was maximum near the wall and minimum at the free surface center. Furthermore, in the light of the steady state study, Roh and Son [18] investigated the natural convection in a Liquefied Natural Gas (LNG) tank using the commercial CFD software FLUENT. Their major results revealed that heat transfer rate was strongly related to liquid-solid contact area. In addition, this heat transfer was essentially caused by the liquid region rather than by the vapor region.
In order to avoid fuel losses, some authors proposed the re-liquefaction of the BOG instead of burning it off [19, 20]. Liu et al. [20] proposed a re-liquefying system using the nitrogen liquid. This cooling fluid enters the heat exchanger to re-liquefy the BOG and then the LNG is re-injected into the storage tank. However, very little information is available on solutions based on abating the effect of the heat ingress on the tanks. Therefore, the main purpose of this paper is to attempt to prevent the LNG temperature increase before the formation of the BOG. This would be possible through the creation of baffles cooled with nitrogen that would remove the heat gain in the storage tank. This suggested solution represents compact cooling system integrated in the tank.

\section{Mathematical formulation}

\subsection{Governing equations}

In this work, the cylindrical storage tank, with an aspect ratio $\mathrm{AR}=\frac{1}{2}$, is equipped with cooling baffles (the baffle number $N b=2,3,4,6,8$ or 12) uniformly distributed along the azimuthal direction. Taking into account the periodicity in the azimuthal direction and the symmetry conditions of the problem, the calculation domain is limited to a volume forming $1 /(2 N b)$ of the tank (Fig. 1).

In this study, the flow is treated as three-dimensional and laminar, and the fluid, which corresponds to LNG (Tab. 1) [21], is supposed to be incompressible. The governing equations for steady natural convection, more specifically the continuity, the momentum and the energy equations with the standard Boussinesq approximation are used.

The non-dimensionalized form of the governing equations can be expressed using the following variables:

$$
\begin{gathered}
u=\frac{\boldsymbol{u}}{\boldsymbol{w}_{0}}, v=\frac{\boldsymbol{v}}{\boldsymbol{w}_{0}}, w=\frac{\boldsymbol{w}}{\boldsymbol{w}_{0}}, r=\frac{\boldsymbol{r}}{\boldsymbol{H}}, z=\frac{\boldsymbol{z}}{\boldsymbol{H}}, \\
t=\frac{\boldsymbol{t}}{\left(\frac{\boldsymbol{H}}{w_{0}}\right)}, T=\frac{\left(T-T_{0}\right)}{\Delta T_{0}}, p=\frac{p}{\left(\rho w_{0}^{2}\right)},
\end{gathered}
$$

with $\boldsymbol{w}_{0}=\sqrt{\boldsymbol{g} \boldsymbol{\beta} \boldsymbol{H} \Delta \boldsymbol{T}_{\mathbf{0}}}$ and $\Delta T_{0}=\frac{\varphi_{\ell} \boldsymbol{H}}{\lambda}$.

The final form of the dimensionless governing equations is then written as:

Continuity equation:

$$
\nabla \cdot \vec{V}=0
$$

Momentum equation:

$$
\frac{\partial \overrightarrow{\mathrm{V}}}{\partial t}+\overrightarrow{\mathrm{V}} \cdot \nabla \overrightarrow{\mathrm{V}}=-\nabla p+\sqrt{\frac{P r}{R a}} \nabla^{2} \overrightarrow{\mathrm{V}}+T \vec{e}_{\mathrm{z}} .
$$

Energy equation:

$$
\frac{\partial T}{\partial t}+\overrightarrow{\mathrm{V}} \cdot \nabla T=\frac{1}{\sqrt{R a \cdot P r}} \nabla^{2} T
$$

with $\overrightarrow{\mathbf{V}}$ is the velocity vector $(u, v, w)$. 
These equations are exhaustively dealt with in Ghiaasiaan [22].

\subsection{Boundary conditions}

In this study, we suppose that heat is gained from the surrounding environment through lateral insulated surface of the LNG tank which is equipped with a cooling system. Hence, the main purpose is to reduce the heat gain in order to keep the LNG temperature under the saturation temperature and therefore limit the evaporation rate. Because there is no perfect insulation, heat is transferred into LNG through the insulation walls, which is ascribed to the large temperature differential between the fluid inside the tank and the ambient temperature.

In this present work, the reservoir is subjected to a constant heat flux density through the lateral wall, with adiabatic top and bottom surfaces:

On the lateral wall:

$$
\frac{\partial T}{\partial r}=1
$$

On the bottom and top surfaces:

$$
\frac{\partial T}{\partial z}=0
$$

On the other hand, the LNG heat gains are removed by baffles cooled with nitrogen. The temperature of the cooling liquid (nitrogen) is supposed to be constant. Therefore, the boundary condition at the baffles is:

$$
T_{\mathrm{b}}=0 \text {. }
$$

For all the rigid surface, no-slip condition is used, and at the symmetry vertical planes (plane midway between two consecutive baffles) of the tank:

$$
\frac{\partial u}{\partial \theta}=\frac{\partial w}{\partial \theta}=\frac{\partial T}{\partial \theta}=0 ; v=0 .
$$

\section{Numerical method}

\subsection{General features}

The numerical solution of the complete governing equations (1)-(3) is obtained using the finite volume method and the steady laminar regime is reached by way of the false-transient regime method.

The computed domain is subdivided into a number of control volumes $\Omega$ defined in a cylindrical three-dimensional coordinate. A staggered uniform mesh is used as the pressures and the temperatures are located at the middle of the control volumes. However, the velocities are situated on the faces of the control volumes. A hybrid scheme interpolation is used for the spatial discretization. The pressurevelocity coupling was handled by Patankar's SIMPLE algorithm [23]. For temporal discretization, an implicit scheme of alternate directions of Douglas and Gunn [24] was adopted. A more detailed presentation of this resolution algorithm is shown in Figure 2.

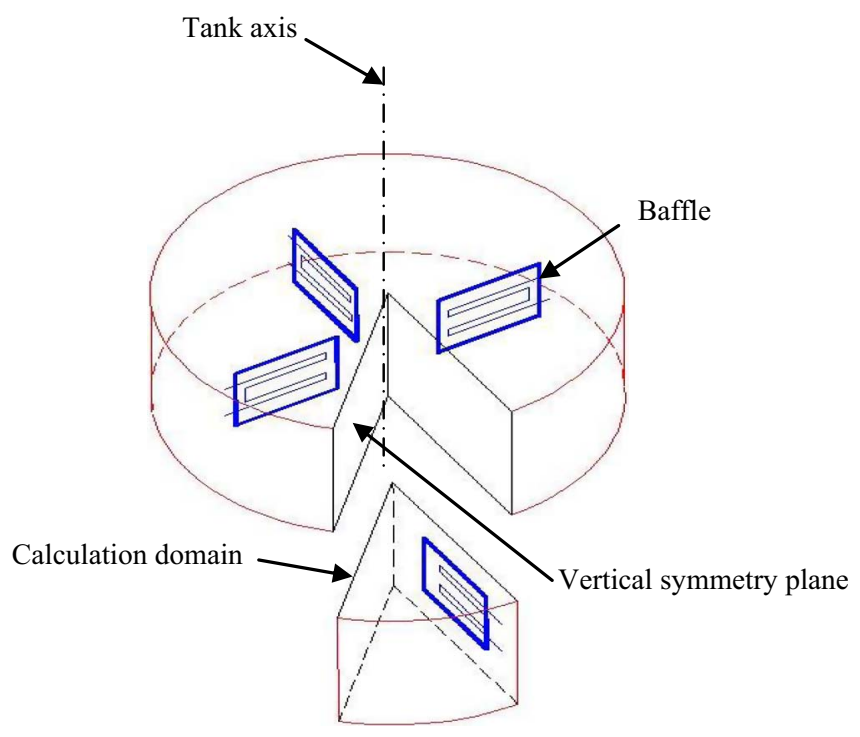

Fig. 1. Schematic of the LNG tank.

Table 1. LNG proprieties [21].

\begin{tabular}{lc}
\hline LNG properties at $-163{ }^{\circ} \mathrm{C}$ and $1 \mathrm{~atm}$ & Values \\
\hline Liquid density, $\rho$ & $424.53 \mathrm{~kg} \mathrm{~m}^{-3}$ \\
Liquid specific heat, $\mathrm{Cp}$ & $3.45 \mathrm{~kJ} \mathrm{~kg}^{-1} \mathrm{~K}^{-1}$ \\
Liquid viscosity, $\mu$ & $1.17810^{-4} \mathrm{~Pa} \mathrm{~s}^{-1}$ \\
Liquid thermal conductivity, $\lambda$ & $0.193 \mathrm{~W} \mathrm{~m}^{-1} \mathrm{~K}^{-1}$ \\
\hline
\end{tabular}

The convergence criterion for pressure, velocity and temperature solutions was set so that the residual fell below the tolerance of $10^{-6}$ and a dimensionless time step $10^{-5}$ was found to be sufficient for producing accurate results at reasonable computed time by respecting the constraint $\mathrm{CFL}_{\max }<1$ in all simulations.

\subsection{Grid independency}

The simulation results $\left(R a=10^{5}, N b=4, \mathrm{AR}=\frac{1}{2}\right)$ for three different mesh densities were compared to verify the grid dependency. Figure 3 shows the dimensionless velocity $\mathrm{w}$ and the dimensionless temperature $T$ along $r$ at $z=0.5$. As shown in Figure 3, the simulation results obtained by fine (294 272 cells) and medium grids (87 856 cells) are quite identical. However, the coarse grid (18 772 cells) results present a discrepancy with the finer grid sizes. Hence, the medium grid was used in the remaining of simulations.

\subsection{Numerical validation}

Due to the lack of experimental studies in cylindrical enclosures, the numerical results of Lemembre and Petit [4] were adopted to validate our model under the same conditions $\left(R a=10^{5}, \operatorname{Pr}=0.7, \mathrm{AR}=\frac{1}{2}\right)$. This two- dimensional model is solved under these conditions: a heating lateral wall side, an adiabatic bottom condition and a 


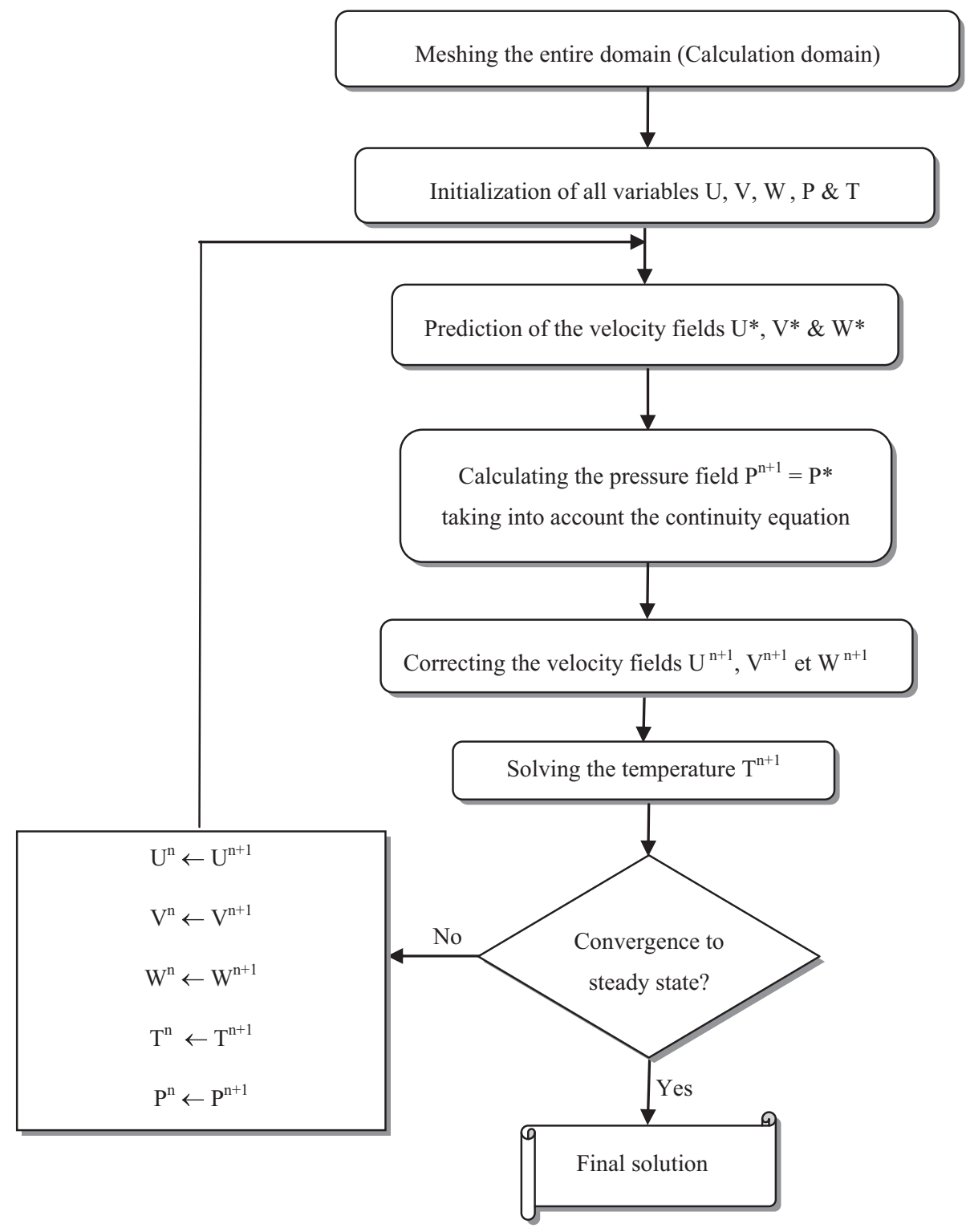

Fig. 2. Flow chart representing the algorithm used to solve the problem.

uniformly cooled top surface in order to obtain a steadystate solution.

As illustrated in Figure 4A, the dimensionless temperature profile agrees well with that obtained by Lemembre, and Petit [4] using a uniform grid $(70 \times 70)$.

As illustrated in Figure 4B, a good agreement was found between the computed dimensionless axial velocity along the radial position and that obtained by Lemembre and Petit [4].

\section{Results and discussion}

The thermo-convective behavior is studied in the LNG cylindrical tank subjected to the heat gain through the lateral wall and cooled by baffles. In function of a numerical simulation, this section will exhibit the main findings related to the effects of baffle position, dimension and number on the stored LNG temperature and flow. The results are given for a thermal Rayleigh number range $\left(R a=10^{3}-10^{7}\right)$, fixed value of the Prandtl $(\operatorname{Pr} \approx 2)$ and aspect ratio $\left(\mathrm{AR}=\frac{1}{2}\right)$.

\subsection{Rayleigh number effect}

Figure 5 exhibits the flow patterns as well as the temperature fields in a vertical plane at an angular position $\theta_{a}=1.2^{\circ}$ from the baffle plane for $N b=4$ and different values of $\operatorname{Ra}\left(10^{3}, 10^{4}, 10^{5}\right)$.

By comparing Figure 5A and B, it appears that the thermal gradient on top of the baffles is more accentuated for $R a=10^{4}$. Thus, when $R a=10^{3}$, the fluid, heated at 


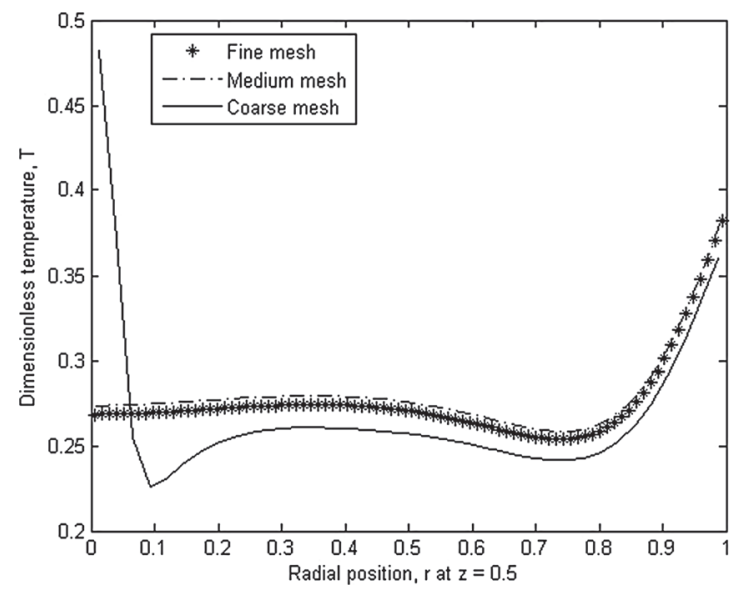

A

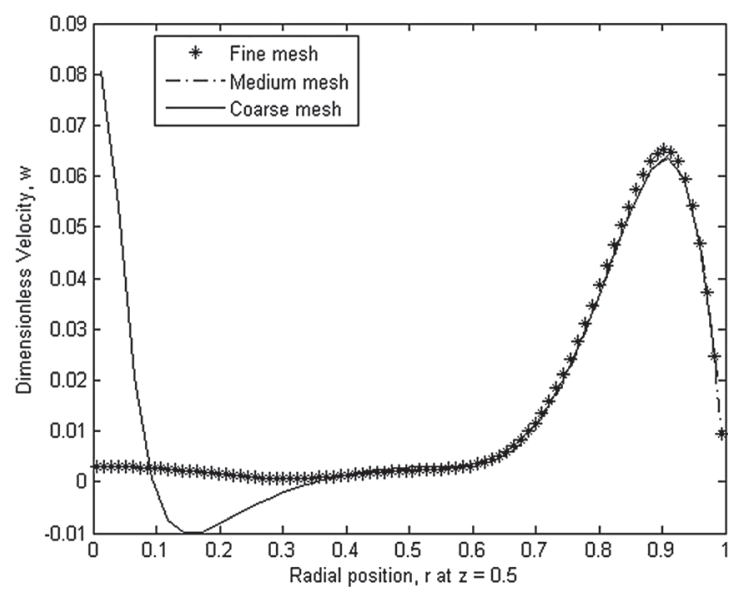

$\mathrm{B}$

Fig. 3. Effect of mesh size on CFD results: (A) $T$ and (B) $w$ along $r$ at $z=0.5$.

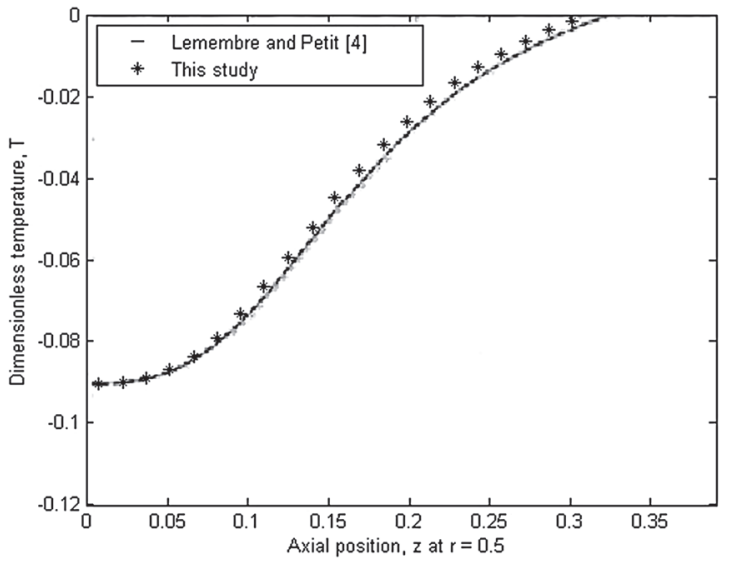

A

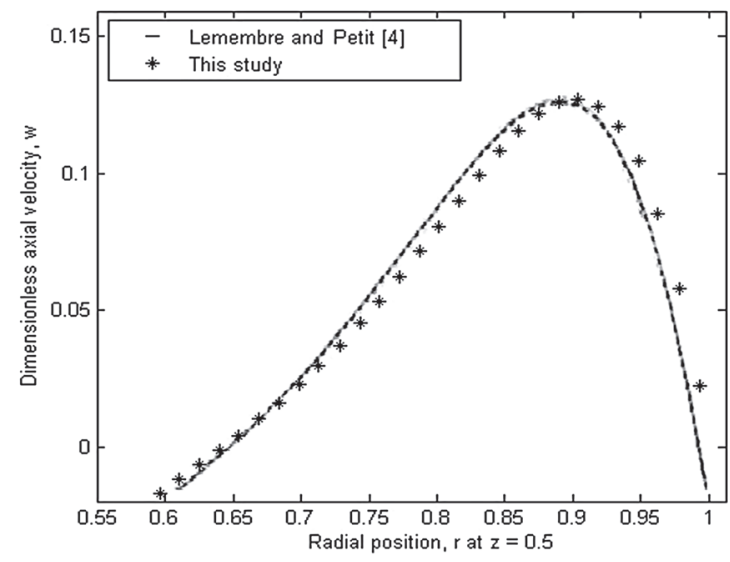

B

Fig. 4. Distribution of $T$ and $w$ at $R a=10^{5} ; \operatorname{Pr}=0.7 ; A l=1 / 2:(\mathrm{A})$ near the bottom at $r=0.5$ and (B) near the wall at $z=0.5$.

the peripheral zone, passes over the baffles and moves downward near the cavity central axis. However, for $R a=10^{4}$, the LNG downs more rapidly and the primary recirculation zone size is reduced. In addition, the flow pattern changes completely when the Rayleigh number reaches $10^{5}$. In fact, for $R a=10^{5}$ a secondary recirculation zone appears in the middle of the tank.

Table 2 shows the Rayleigh number effects on the average and maximum dimensionless temperatures and the maximum dimensionless axial velocity when the tank is equipped with a fixed number of baffles $(N b=4)$. It can be clearly observed that the more the Rayleigh number increases, the more intensive the buoyancy-driven flow, generated by the vertical temperature gradient, becomes. Indeed, the dimensionless velocity increases fivefold from 0.0673 at $R a=10^{5}$ to 0.3486 at $R a=10^{7}$ (Tab. 2).

Simultaneously, with the $R a$ increase, the heat transfer is more important causing a drop of both average and maximum dimensionless temperature inside the LNG tank as is shown in Table 2. This decrease is approximately of $50 \%$ since the average temperature drops from 0.297 at $R a=10^{5}$ to 0.137 and the maximum temperature drops from 0.635 to 0.349 at $R a=10^{7}$.

This finding is confirmed by the horizontal cross section at $z=0.5$ for different Rayleigh numbers, exhibited in Figure 6. For instance, as can be clearly seen in Figure 6A, for $R a=10^{3}$, the heat transfer is dominant per conductive regime. Hence, at the sidewall of the tank, the isotherms are slightly distorted by the movement and the liquid temperature is significantly important. Indeed, as is shown in Table 2, the maximum dimensionless temperature $T_{\max }$ is equal to 0.899. However, as can be seen in Figure 6B and $\mathrm{C}$, with $R a=10^{4}$ and $R a=10^{5}$, the form of the isotherms changes indicating that the hot area along the tank sidewalls, caused by the upward buoyancy has become thinner and the central zone has grown more homogenous. 


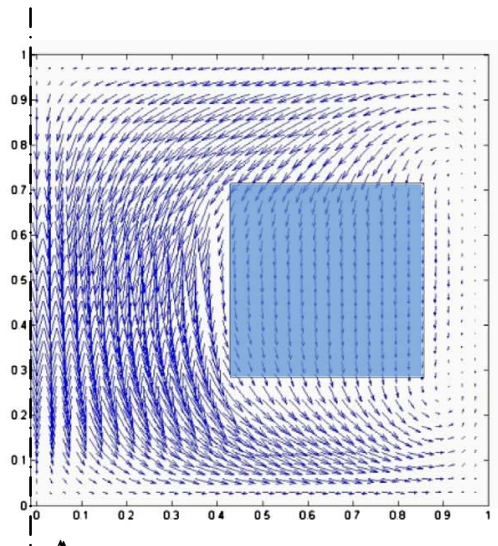

A

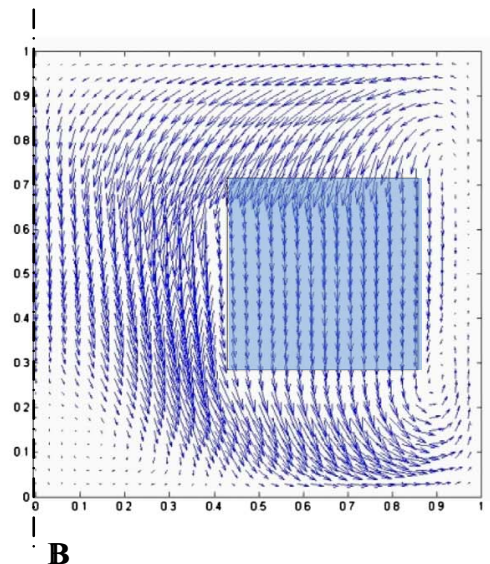$$
\text { I }
$$

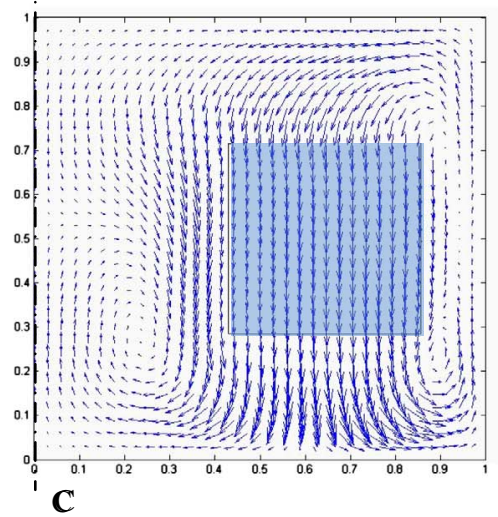

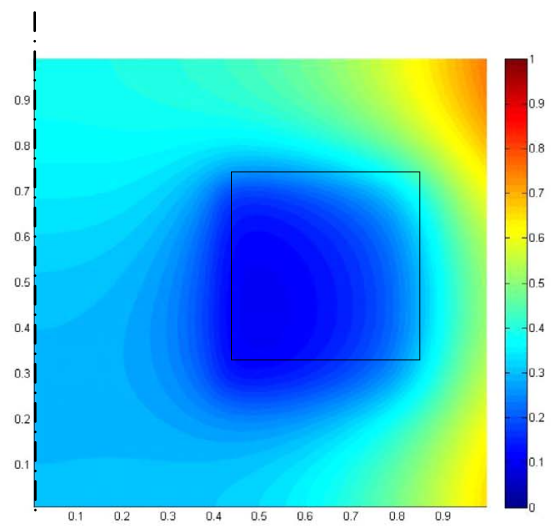
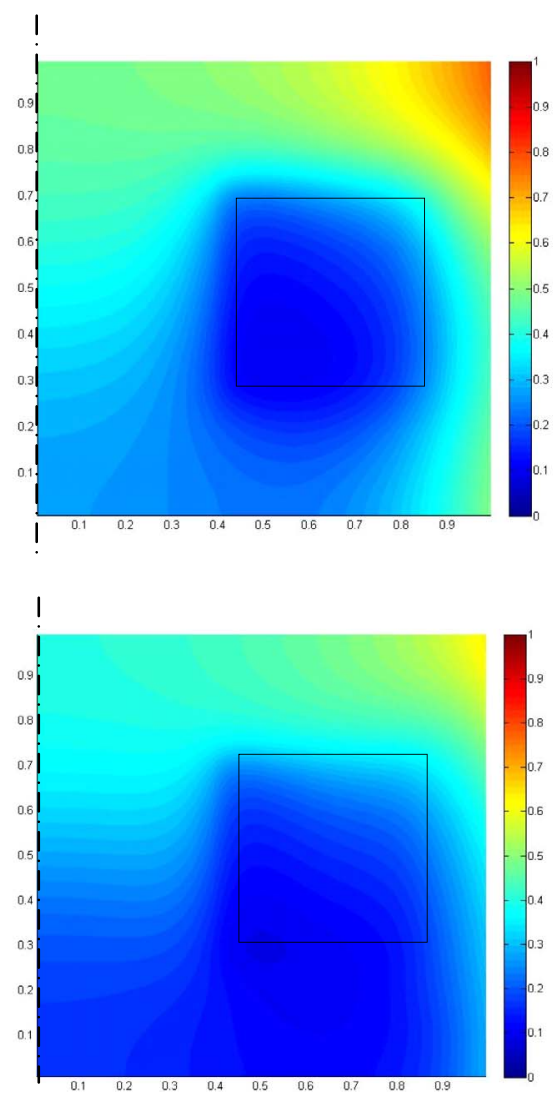

Fig. 5. Velocity and temperature distributions in a vertical plane at $\theta_{\mathrm{a}}=1.2^{\circ}$ for $N b=4$ and different values of Rayleigh: (A) $R a=10^{3}$, (B) $R a=10^{4}$ and (C) $R a=10^{5}$.

\subsection{Axial baffle position effect}

To limit the LNG temperature increase and then the BOG, it is necessary to understand the baffle position effect on the thermo-convective behavior of the liquid inside the storage tank. For this purpose, three vertical positions of the baffle are studied: the bottom, the middle and the top of the tank while keeping the other three variables constant; namely, the Rayleigh number $\left(R a=10^{5}\right)$, the aspect ratio $\left(\mathrm{AR}=\frac{1}{2}\right)$ and the number of cooling systems $(N b=4)$.
Table 2. Rayleigh number effects on $T_{\mathrm{av}}, T_{\max }$ and $w_{\max }$ for $N b=4$.

\begin{tabular}{lccc}
\hline Rayleigh number & $T_{\mathrm{av}}$ & $T_{\max }$ & $w_{\max }$ \\
\hline $10^{3}$ & 0.478 & 0.899 & 0.0063 \\
$10^{4}$ & 0.421 & 0.835 & 0.0306 \\
$10^{5}$ & 0.297 & 0.635 & 0.0673 \\
$10^{6}$ & 0.203 & 0.471 & 0.1502 \\
$10^{7}$ & 0.137 & 0.349 & 0.3486 \\
\hline
\end{tabular}



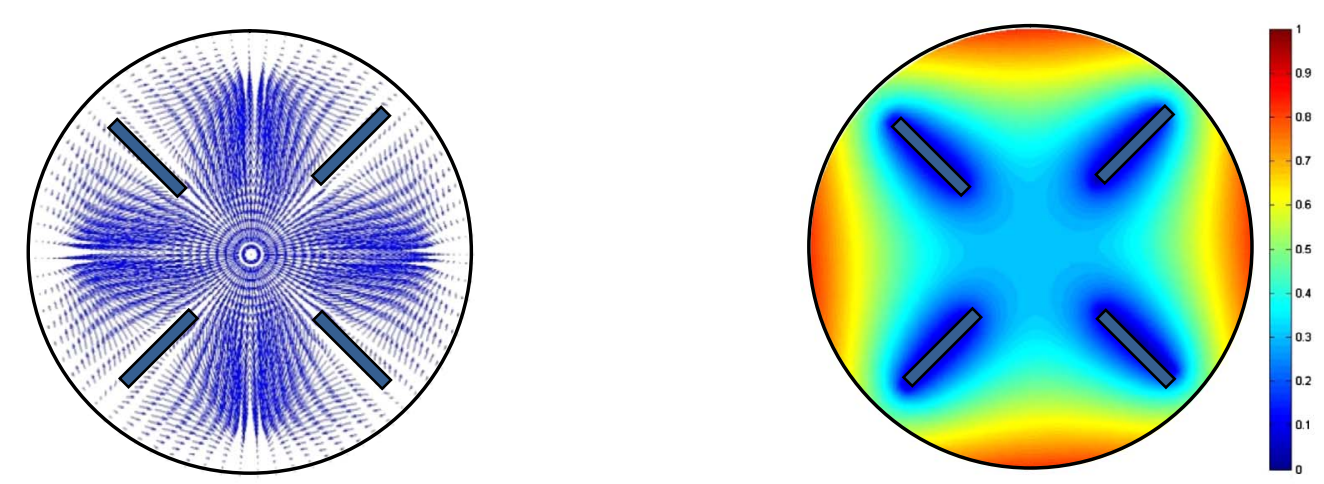

A
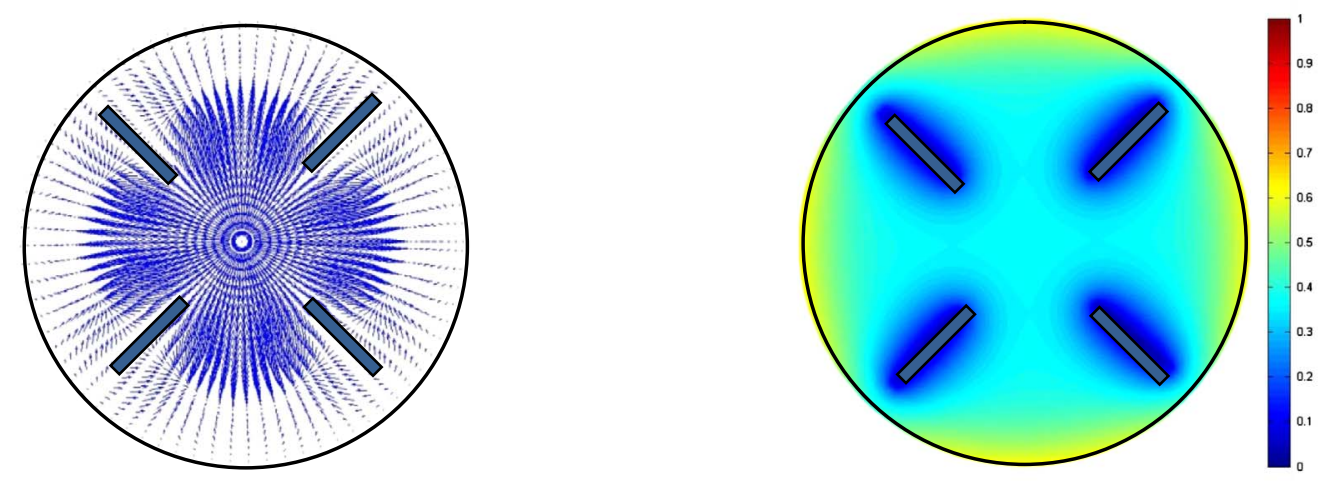

B
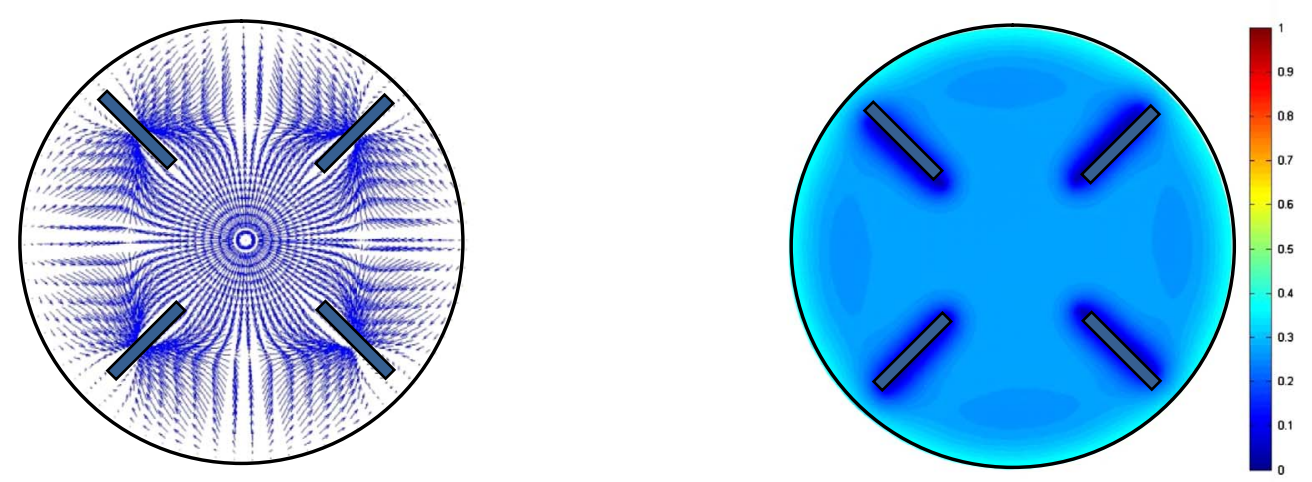

C

Fig. 6. Cross section of an LNG tank equipped with baffles: the effect of different Rayleigh numbers: $(\mathrm{A}) R a=10^{3},(\mathrm{~B}) R a=10^{4}$ and (C) $R a=10^{5}$.

Figure $7 \mathrm{~A}$ presents the first configuration where the baffle is at the bottom of the reservoir leading to the formation of thermal stratification at the top of the tank. This is due to the fact that warm LNG is lighter than the cold one. In addition, two re-circulations appear; namely, the cold fluid next to the baffle moving downward and creating the first re-circulation zone on the right. Secondly, on the left, located at the bottom side, another recirculation helps the formation of stratified fluid. Table 3 reveals that at this position the average temperature inside the tank rises drastically, $T_{\mathrm{av}}=0.427$ revealing an inefficient cooling of the liquid and indicating the possibility of the apparition of a new recirculation zone, at the top right side of the tank, where the temperature can reach $T_{\max }=0.839$.

In contrast, Figure 7B shows a second configuration with the cooling system displaced to the top of the tank. This disposition clearly prevents the formation of the stratification at the top of the tank. This observation can be explained by the fact that with this new position, the fluid, which is getting warmer along the sidewall tank, is cooled by the baffle directly as soon as it reaches the top. The LNG with heavier density sinks down into the bottom of the tank reaching the strongest velocity of $w_{\max }=0.0853$ (Tab. 3). Thus, the fluid average temperature decreases 

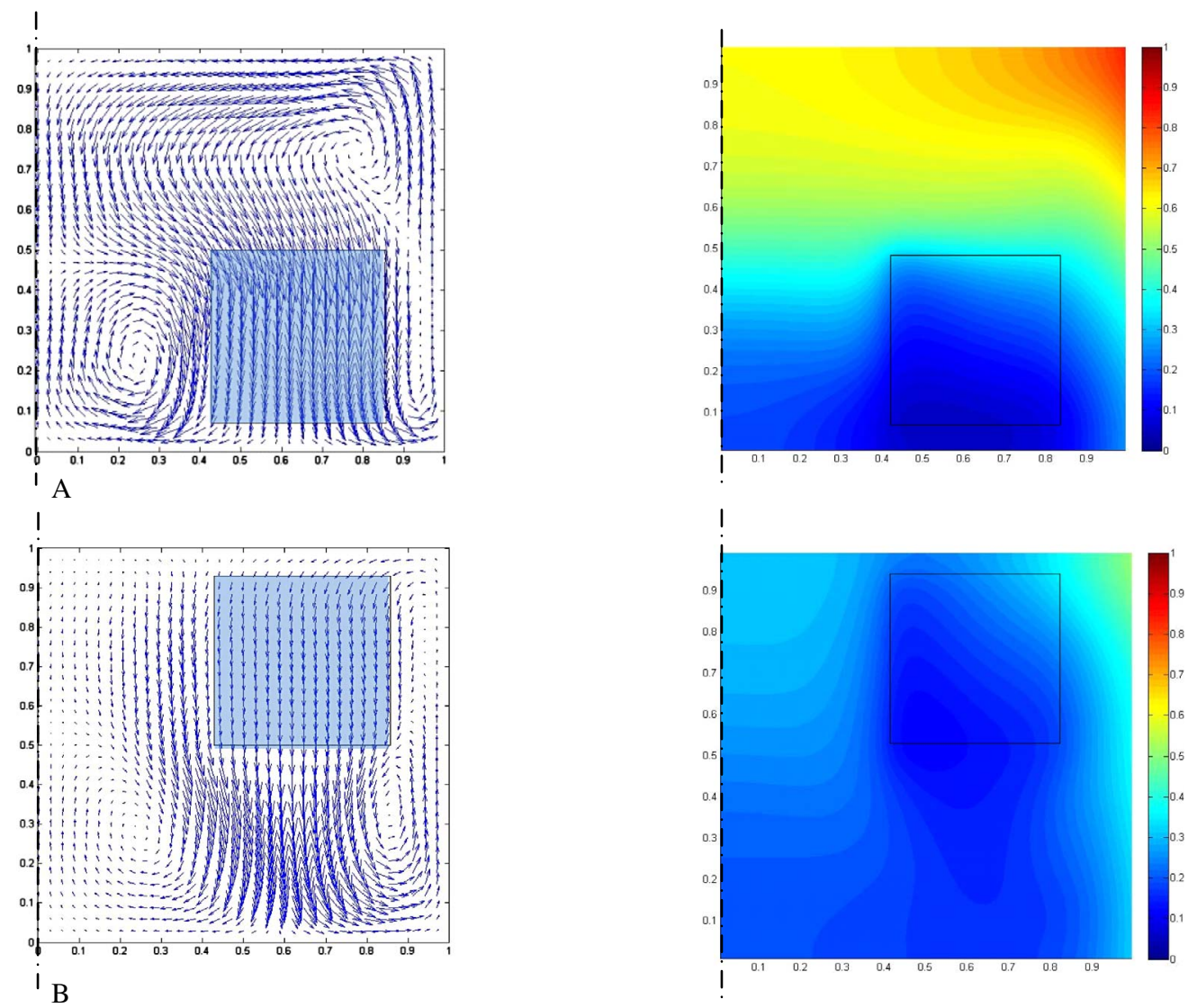

Fig. 7. The effect of the top/bottom positions of the baffles on LNG; $\theta_{\mathrm{a}}=1.2^{\circ} ; R a=10^{5} ; N b=4$ : (A) Bottom position, (B) Top position.

Table 3. Axial baffle position effect on $T_{\text {av }}, T_{\max }$ and $w_{\max }$ for $R a=10^{5}$ and $N b=4$.

\begin{tabular}{lccc}
\hline Axial baffle position & $T_{\mathrm{av}}$ & $T_{\max }$ & $w_{\max }$ \\
\hline Bottom & 0.427 & 0.839 & 0.0502 \\
Middle & 0.297 & 0.635 & 0.0673 \\
Top & 0.267 & 0.553 & 0.0853 \\
\hline
\end{tabular}

inside the tank, $T_{\mathrm{av}}=0.267$. Hence, a homogeneous mixing of the LNG occurs resulting in an effective cooling for the liquid. This would minimize the impact of the heat gain transferred to the liquid from outside.

Thus, it can be concluded with much certainty that firstly, the fluid is well cooled around the baffle for the three positions. Secondly, the temperature of LNG inside the tank strongly depends on the baffle position as shown in Figures 5C, 7A and B. Thirdly, the optimum cooling yield can be obtained by installing baffles at the top of the tank. This would improve the cooling efficiency of the baffles via decreasing the maximum temperature by $34 \%$ as can be seen in Figure 7B. Finally, in addition to the efficiency in cooling, this position of the baffles can improve the motion fluidity of the liquid by up to $70 \%$ and prevent the stratification of LNG in the tank as can seen in Table 3.

\subsection{Radial baffle position effect}

Figure 8 presents two others configurations where the baffles are installed radially close to the tank axis (Fig. 8A) and at the middle of the tank (Fig. 8B). In addition, Table 4 exhibits the radial position effect on the average and maximum dimensionless temperatures and the maximum dimensionless axial velocity for the three radial positions. It can be clearly observed as we move the baffle toward the lateral wall, the recirculation zone close to the tank wall becomes smaller and the LNG, near the lateral wall, is colder (Figs. 7B, 8A and B). The hot zones, almost located near the lateral wall, shrink and the maximum temperature of the fluid inside the tank drops to reach $T_{\max }=0.553$ (Tab. 4). Thus, these hot zones which are located near the lateral wall, as confirmed by Khelifi Touhami et al. [17], are reduced when placing the baffle at that place. However, moving the baffles, radially far away from the lateral wall, would have less impact on minimizing the temperature inside the LNG tank and it would limit the role of the cooling system.

\subsection{Baffle size effect}

The effect of baffle size, especially the baffle height, on the thermo-convective behavior of LNG is studied. For this purpose, two others configurations were proposed: the first 

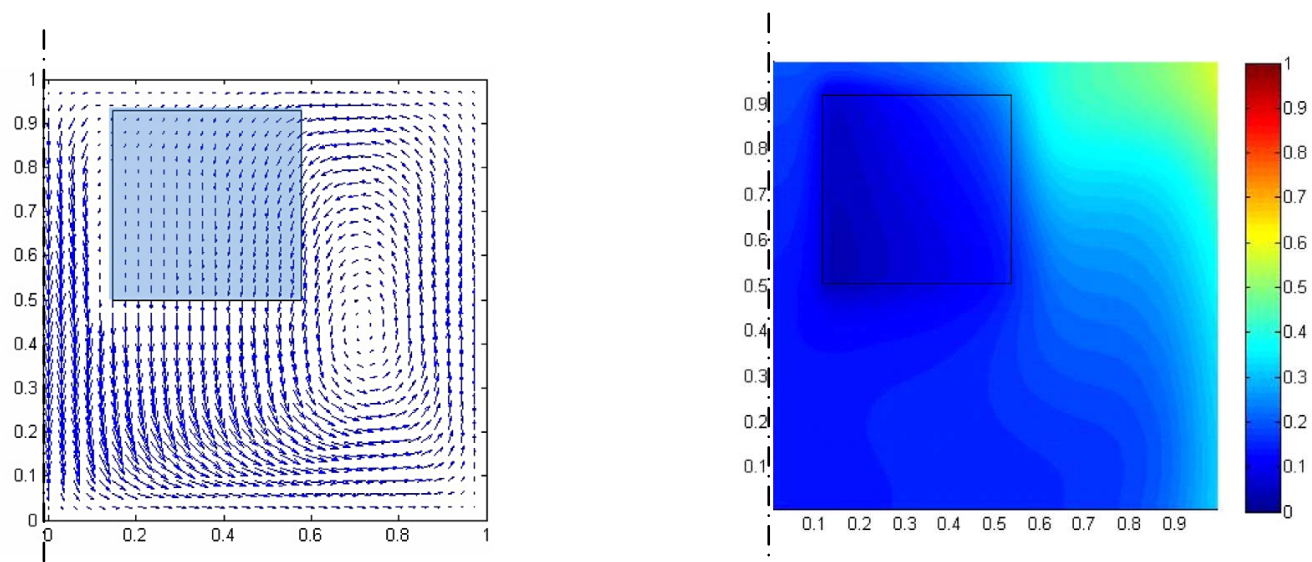

A
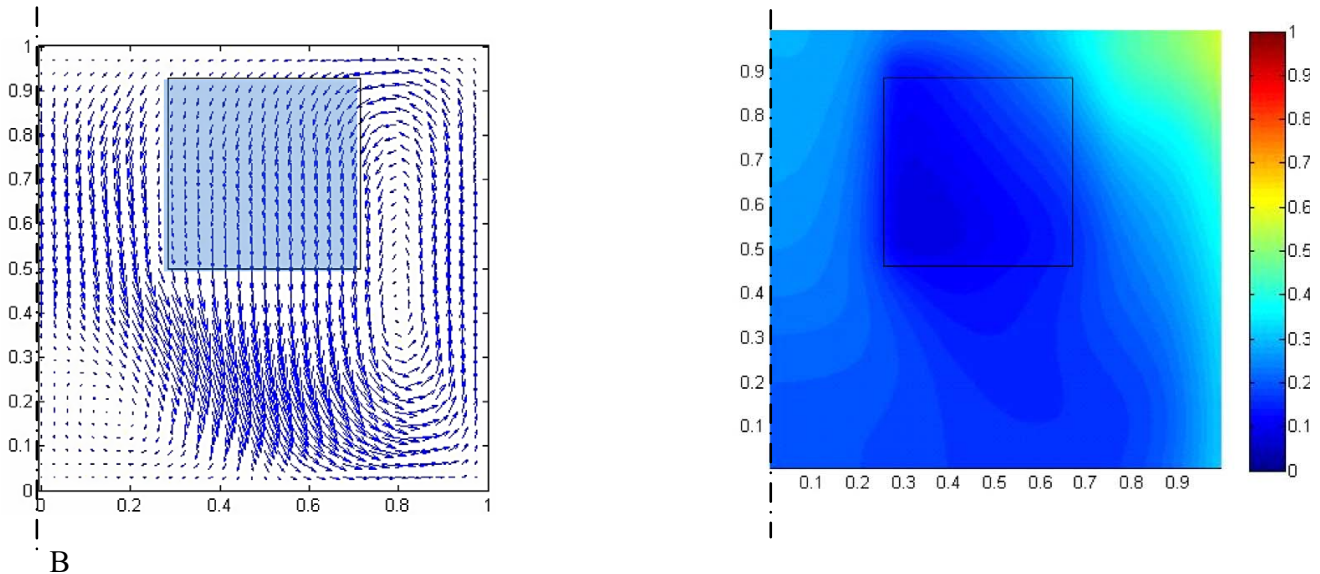

Fig. 8. The effect of the radial position on LNG; $\theta_{\mathrm{a}}=1.2^{\circ} ; R a=10^{5} ; N b=4$ : (A) close to the tank axis, (B) at the center of the tank.

Table 4. Radial baffle position effect on $T_{\mathrm{av}}, T_{\max }$ and $w_{\max }$ for $R a=10^{5}$ and $N b=4$.

\begin{tabular}{lccc}
\hline Radial baffle position & $T_{\mathrm{av}}$ & $T_{\max }$ & $w_{\max }$ \\
\hline Close to the tank axis & 0.269 & 0.580 & 0.0731 \\
At the middle of the tank & 0.269 & 0.571 & 0.0839 \\
Close to the lateral wall & 0.267 & 0.553 & 0.0853 \\
\hline
\end{tabular}

configuration (Fig. 9A) with a height equal to one and a half the height of top position configuration and the second configuration (Fig. 9B) with a height equal to twice the height of top position configuration.

Figure 9 shows the effect of baffle-size increase on the temperature of LNG tanks. Although the baffle exchange surface is doubled, it contributes only a $13 \%$ decrease, as illustrated in Table 5. This poor contribution can be explained by the fact that increasing the dimension of the baffle exchange surface breaks the fluid movement and therefore, reduces the maximum velocity by $12 \%$ as shown in Table 5. Such a break would limit the temperature distribution in the LNG tank. Hence, it can be concluded that the baffle size has no significant effect on the temperature distribution inside the tank.

\subsection{Baffle number effect}

Figure 10 displays dimensionless velocity and temperature fields in a vertical plane at a different angular position from the baffle plane and for different baffle numbers at a constant Rayleigh number $R a=10^{5}$. For $N b=2$, thermal stratification forms at the top of the tank as a result of the low temperature effect on LNG in the tank. Table 6 provides more details on the baffle number effects on the average and maximum dimensionless temperatures, for $R a=10^{5}$. It can be clearly seen that the greater the baffle number is, the lower the average and the maximum temperatures become.

For $N b \leq 6$, the representations confirm that every configuration has two-roll flows. The first one develops near the side-wall of the LNG tank. This roll flow can be ascribed to the fact that fluid, with light density, moves upward along the lateral wall of the tank. Therefore, LNG is cooled by the baffle and becomes heavier. Because of this fact, the fluid is forced to move downward. Consequently, 


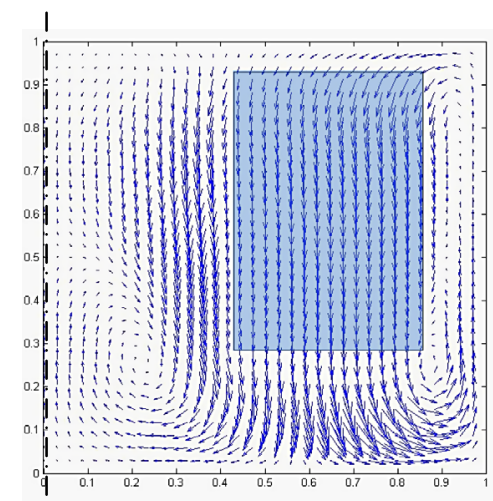

A

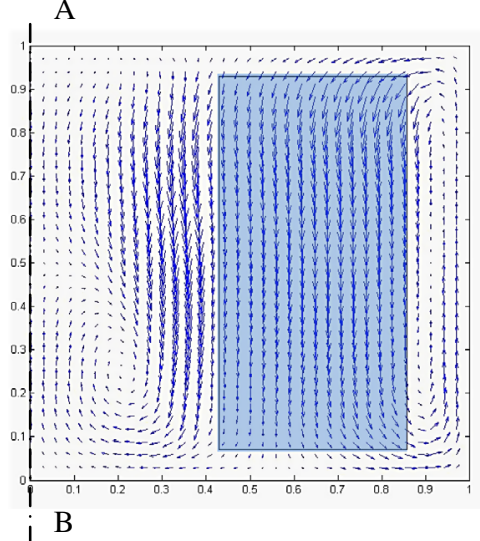

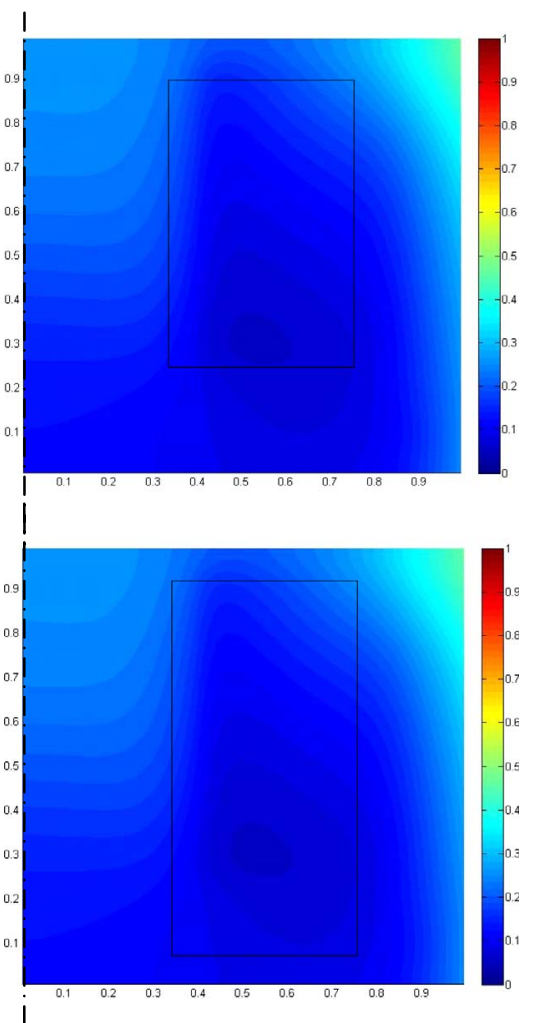

i

Fig. 9. Effect of baffle-size on LNG tank. $\theta_{\mathrm{a}}=1.2^{\circ} ; R a=105 ; N b=4$ : (A) 1st configuration, (B) 2nd configuration.

Table 5. Baffle dimension effect on $T_{\mathrm{av}}, T_{\max }$ and $w_{\max }$ for $R a=10^{5}$ and $N b=4$.

\begin{tabular}{lccc}
\hline Baffle surface, $S_{\mathrm{b}} x$ & $T_{\mathrm{av}}$ & $T_{\max }$ & $w_{\max }$ \\
\hline 1 & 0.267 & 0.553 & 0.0853 \\
1.5 & 0.208 & 0.500 & 0.0798 \\
2 & 0.185 & 0.482 & 0.0756 \\
\hline
\end{tabular}

a counterclockwise recirculation along the tank side wall is triggered. The second roll flow begins when the heavier cooled fluid reaches the bottom. Then, it changes direction moving upward in a clockwise direction along the tank axis. As it climbs up to reach the top, its temperature rises and it becomes lighter. At this stage, the LNG is cooled again by the baffle and the anticlockwise recirculation direction restarts.

However, for $N b>6$, the fluid maximum and average dimensionless temperatures drop significantly indicating that LNG has become almost homogenous. As a consequence, the fluid movement changes so that only one roll flow appears along the tank side wall.

Table 6 also exhibits the variation of maximum dimensionless axial velocity at $R a=10^{5}$ for different numbers of baffles. It can be observed that the more baffles there are in the tank, the more enhanced dimensionless maximum velocity is obtained. This improvement in the velocity contributes to the LNG temperature decrease and to its homogenization. Nevertheless, for $N b=12$, the velocity drops indicating that the flow finds little space to move in.
On another scale, the increase of the number of baffles in the LNG tank reduces the space between them. Therefore, it will necessarily enhance the heat transfer between the cooling system and the fluid. Simultaneously, this increase of the number of baffle will necessarily reinforce the radial component of velocity at the expense of the angular one, which implies a better dynamics of the fluid. Moreover, by decreasing the number of baffles, and respectively increasing the distance between the cooling systems, less velocity intensity is observed especially far away from the baffle.

\subsection{Nusselt number correlation}

To better understand the heat transfer phenomena, it is interesting to study the average Nusselt number on the lateral surface $\mathrm{Nu}_{l}$ and the average Nusselt number on the baffle $\mathrm{Nu}_{b}$ for the top position case. These parameters are expressed as follows:

On the lateral surface:

$$
N u_{1}=\frac{\overline{\boldsymbol{h}}_{1} \boldsymbol{D}}{\boldsymbol{\lambda}}=\frac{1}{\operatorname{AR}\left(T_{1}-T_{\mathrm{av}}\right)} .
$$

On the baffle:

$$
N u_{\mathrm{b}}=\frac{\overline{\boldsymbol{h}}_{b} \boldsymbol{H}_{\boldsymbol{b}}}{\boldsymbol{\lambda}}=\frac{-1}{L_{\mathrm{b}} T_{\mathrm{av}}} \iint_{S_{\mathrm{b}}} \frac{\partial T}{r \partial \theta} \cdot \mathrm{d} S_{\mathrm{b}}
$$

with $\boldsymbol{L}_{\mathrm{b}}=\frac{\boldsymbol{L}_{\mathrm{b}}}{\boldsymbol{H}}$ is the dimensionless width of baffle. 


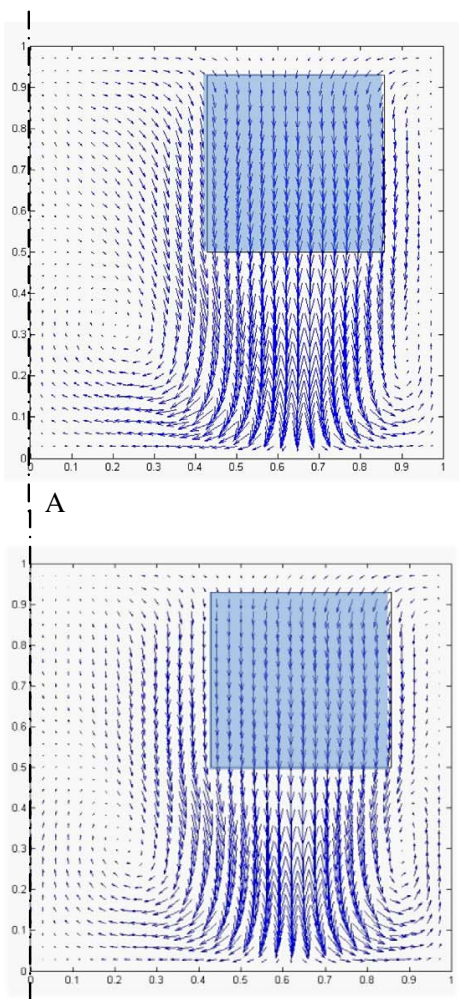

B

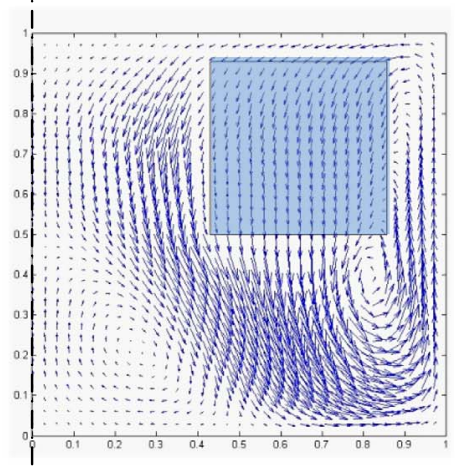

i C

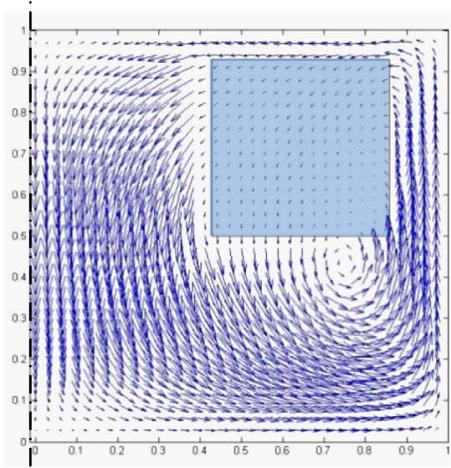

D
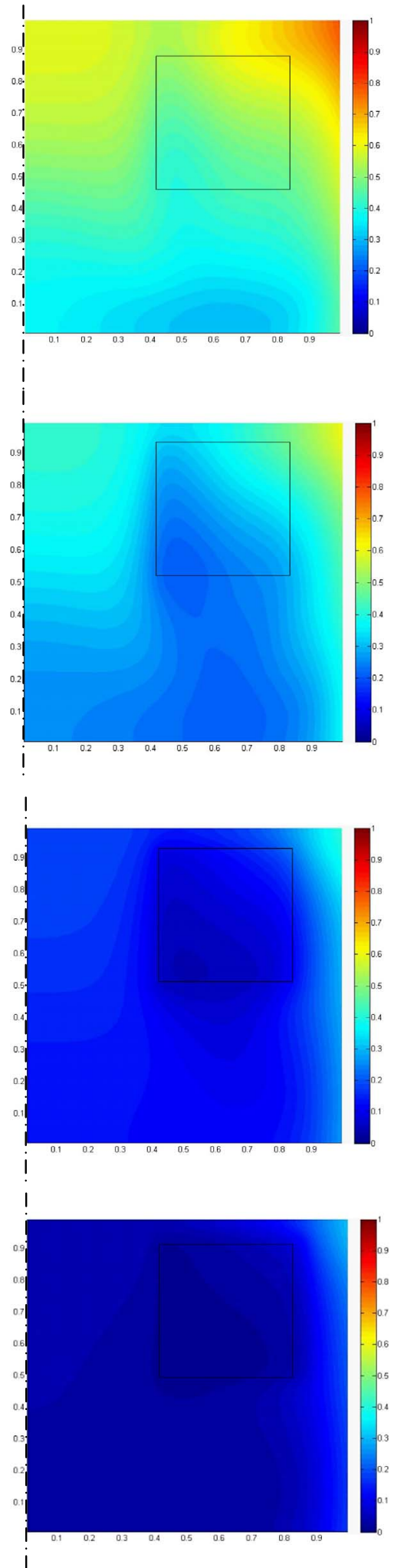

Fig. 10. The effect of the number of baffles on the LNG at $R a=10^{5}$ : (A) $\theta_{\mathrm{a}}=2.3^{\circ} ; N b=2,(\mathrm{~B}) \theta_{\mathrm{a}}=1.5^{\circ} ; N b=3,(\mathrm{C}) \theta_{\mathrm{a}}=0.8^{\circ}$; $N b=6$, (D) $\theta_{\mathrm{a}}=0.4^{\circ} ; N b=12$. 
Table 6. Baffle number effects on $T_{\mathrm{av}}, T_{\max }$ and $w_{\max }$ for $R a=10^{5}$.

\begin{tabular}{lccc}
\hline Baffle number & $T_{\text {av }}$ & $T_{\max }$ & $w_{\max }$ \\
\hline 2 & 0.497 & 0.814 & 0.0713 \\
3 & 0.349 & 0.647 & 0.0787 \\
4 & 0.267 & 0.553 & 0.0853 \\
6 & 0.180 & 0.452 & 0.0943 \\
8 & 0.131 & 0.398 & 0.0942 \\
12 & 0.074 & 0.329 & 0.0850 \\
\hline
\end{tabular}

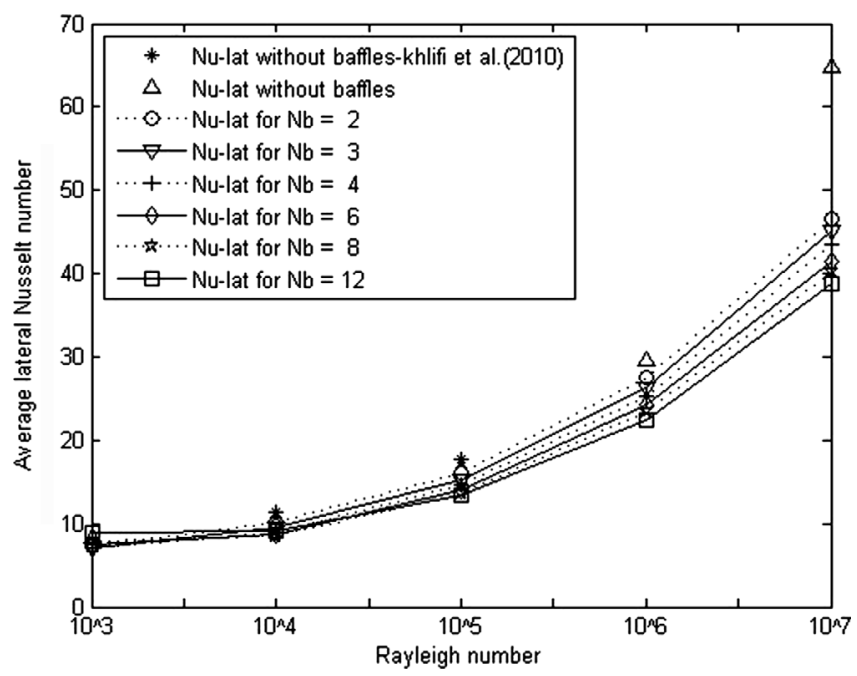

Fig. 11. Distribution of average lateral Nusselt number in function of Rayleigh number for various baffle numbers.

As shown in Figure 11, our results agree well with that obtained by Khelifi Touhami et al. [17]. In fact, $N u_{1}$ computed without baffle is a little greater than other cases due to the absence of baffles as obstacles. Hence, the LNG finds more space to move leading to high velocity intensity and an increase of LNG temperature inside the reservoir compared to other configurations. In the present of cooling systems, the fluid slows down as the baffle plays the role of an obstacle. When Rayleigh number is greater than $10^{4}$, the global tendency is the decrease of lateral Nusselt number by increasing the baffle number. The $N u_{1}$ can be correlated using equation (10) established for different baffles number and $10^{4} \leq R a \leq 10^{7}$ as follows:

$$
N u_{1}=4.19+0.5 R a^{0.28} N b^{-0.12} .
$$

In Figure 12, the graph presents the values of $N u_{\mathrm{b}}$ indicating that heat transfer between the cooling system and the LNG is enhanced with increasing $R a$. By ensuring more baffles and, thus, lowering temperature inside the tank, an effective cooling system is obtained. However, for $R a \geq 10^{5}$ and by increasing baffle number, $N u_{\mathrm{b}}$ decreases. For more understanding, a correlation has been established for $N u_{\mathrm{b}}$ using equation (11) for $10^{4} \leq R a \leq 10^{7}$ as follows:

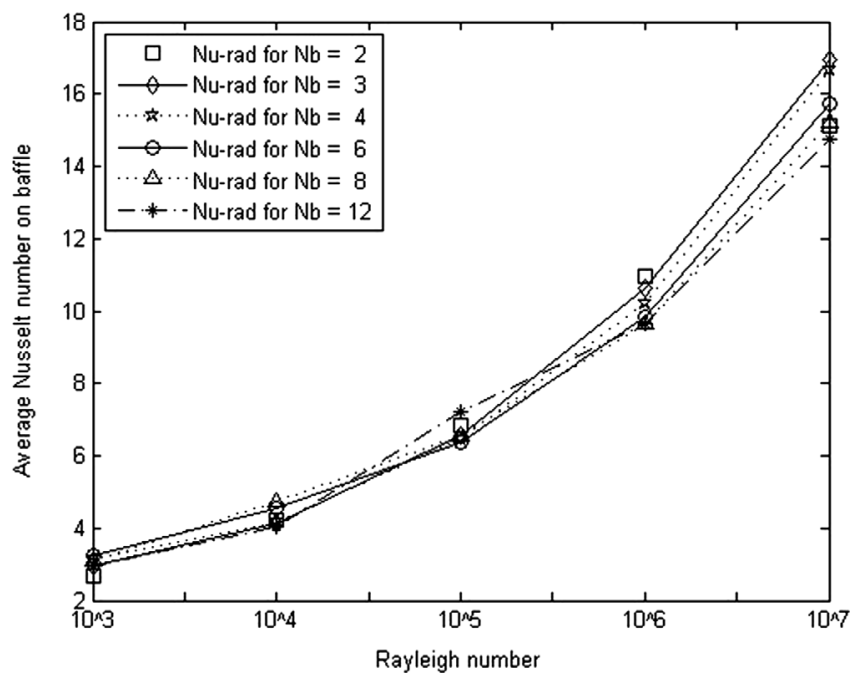

Fig. 12. Distribution of average Nusselt number on the baffle in function of Rayleigh number for various baffle numbers.

$$
N u_{\mathrm{b}}=0.84 R a^{0.18} N b^{-0.04}
$$

\section{Conclusion}

This study attempted to numerically simulate the steady state of heat transfer in a storage tank filled with LNG and cooled by baffles. By using a cooling system to reduce the heat gain, it was expected to reduce the possibility of BOG occurring inside the storage tank and minimize the LNG loss.

Based on a three-dimensional mass, momentum and energy conservation equations, which are solved in the cylindrical co-ordinates, a parametric study of steady state at laminar regime was investigated. The velocity and temperature distributions, for different Rayleigh numbers $\left(R a=10^{3}, 10^{4}, 10^{5}\right)$ and for various baffle numbers $(N b=2,3,4,6,8,12)$, are presented and discussed. Additionally, the influence of the cooling baffle disposition and size, on the heat transfer, is studied to determine the optimal geometric conditions for the cooling system. Finally, for a design purpose, correlations were made for average Nusselt number $N u_{1}$ and $N u_{\mathrm{b}}$ taking into account the number of baffles for $10^{4} \leq R a \leq 10^{7}$.

The main findings of the study can be summarized as follows. Firstly, it was observed that the heat gain acquired from the tank sidewalls causes the LNG to move upward. Simultaneously, the cold liquid sinks down under the effect of its weight increase caused by the lower temperature. The second finding was related to the effect of the increase of $R a$. The fluid flow becomes more important. Therefore, the heat transfer between the baffles and the LNG is more significant causing the drop of both fluid average and maximum dimensionless temperatures inside the tank. The third important finding was about the optimum position of the baffles. This work revealed that the cooling system would be most efficient when placed at the top of the tank since it reduces the stratification zones of the LNG. The fourth finding revealed that for a constant $R a=10^{5}$, the increase 
of number of baffles from 2 to 12 did yield a significant decrease in the average dimensionless temperature inside the LNG tank as follows: from 2 to 4 baffles, a reduction of the average temperature by about $25 \%$ per one baffle is noticed, from 4 to 8 baffles, the average temperature drops by about $13 \%$ per one baffle and from 8 to 12 baffles, by adding 4 baffles a total drop by $44 \%$ is obtained. Thus, the average temperature decreases by about $11 \%$ per one baffle. Finally, for an efficient cooling system of an LNG tank, that would save LNG and reduce BOG, this work would recommend the installation of six top baffles near the wall of the tank.

Acknowledgments. The authors would like to thank Dr. Ayadi Hajji for his help with proofreading, editing and correcting the English of the manuscript.

\section{References}

1 Chen Q.S., Wegrzyn J., Prasad V. (2004) Analysis of temperature and pressure changes in liquefied natural gas (LNG) cryogenic tanks, Cryogenics 44, 701-709.

2 Ren J., Zhang H., Bi M., Yu J., Sun S. (2017) Numerical investigation of the coupled heat transfer of liquefied gas storage tanks, Int. J. Hydrogen Energy 42, 24222-24228.

3 Zellouf Y., Portannier B. (2011) First step in optimizing LNG storages for offshore terminals, J. Nat. Gas Sci. Eng. 3, $582-590$

4 Lemembre A., Petit J.P. (1998) Laminar natural convection in a laterally heated and upper cooled vertical cylindrical enclosure, Int. J. Heat Mass Trans. 41, 2437-2454.

5 Papanicolaou E., Belessiotis V. (2002) Transient natural convection in a cylindrical enclosure at high Rayleigh, Int. J. Heat Mass Trans. 45, 1425-1444.

6 Ginestet S., Le Bot C. (2018) Evaporation flow assessment from petroleum product storage tanks exposed to fire conditions, Oil Gas Sci. Technol. - Rev. IFP Energies nouvelles 73, 27.

7 Daney D.E. (1976) Turbulent natural convection of liquid deuterium, hydrogen and nitrogen within enclosed vessels, Int. J. Heat Mass Trans. 19, 431-441.

8 Evans L.B., Reid R.C. (1968) Transient natural convection in vertical cylinder, AIChE J. 14, 251-259.

9 Liang S.F., Vidal A., Acrivos A. (1969) Buoyancy-driven convection in cylindrical geometries, J. Fluid Mech. 36, 239-256.
10 Mallinson G.D., Davis G.D.V. (1977) Three-dimensional natural convection in a box: A numerical study, J. Fluid Mech. 83, 11-38.

11 Lee H.S., Jung J.H., Yoon H.S. (2013) A numerical study of three dimensional natural convection in a differentially heated cubical enclosure, Proceedings of the 2013 International Conference on Mechanics, Fluids, Heat, Elasticity and Electromagnetic Fields.

12 Schneider S., Straub J. (1992) Laminar natural convection in a cylindrical enclosure with different end temperatures, Int. J. Heat Mass Trans. 35, 545-557.

13 Ma D.J., Henry D., Hadid H. Ben (2005) Three-dimensional numerical study of natural convection in vertical cylinders partially heated from the side, Phys. Fluids 17, 1-12.

14 De Césaro Oliveski R. (2013) Correlation for the cooling process of vertical storage tanks under natural convection for high Prandtl number, Int. J. Heat Mass Trans. 57, 292-298.

15 Rodríguez I., Castro J., Pérez-Segarra C.D., Oliva A. (2009) Unsteady numerical simulation of the cooling process of vertical storage tanks under laminar natural convection, Int. J. Therm. Sci. 48, 708-721.

16 Jourda P., Probert S.D. (1991) Heat-transfer considerations for large liquefied-natural-gas storage tanks, Appl. Energy 38, 263-282.

17 Khelifi Touhami M.S., Benbrik A., Lemonnier D., Blay D. (2010) Laminar natural convection flow in a cylindrical cavity application to the storage of LNG, J. Pet. Sci. Eng. 71, 126-132.

18 Roh S., Son G. (2012) Numerical study of natural convection in a liquefied natural gas tank, J. Mech. Sci. Technol. 26, 3133-3140.

19 Shin Y., Lee Y.P. (2009) Design of a boil-off natural gas reliquefaction control system for LNG carriers, Appl. Energy $\mathbf{8 6}$, $37-44$.

20 Liu S., Li X., Huo Y., Li H. (2015) An analysis of the primary energy consumed by the re-liquefaction of boil-off gas of LNG storage tank, Energy Proc. 75, 3315-3321.

21 Guyer E.C., Brownell D.E. (1999) Handbook of applied thermal design, 2nd edn., Taylor \& Francis, London.

22 Ghiaasiaan S.M. (2011) Convective heat and mass transfer, Cambridge University Press, New York.

23 Patankar S. (1980) Numerical heat transfer and fluid flow. Series in computational methods in mechanics and thermal sciences, McGraw Hill, New York.

24 Douglas J., Gunn J.E. (1964) A general formulation of alternating direction methods, Num. Math. 6, 428. 